\title{
Evolution of CYP2J19, a gene involved in colour vision and red coloration in birds: positive selection in the face of conservation and pleiotropy
}

\author{
Hanlu Twyman ${ }^{1}$, Staffan Andersson ${ }^{2}$ and Nicholas I. Mundy ${ }^{1 *}$
}

\begin{abstract}
Background: Exaggerated signals, such as brilliant colours, are usually assumed to evolve through antagonistic coevolution between senders and receivers, but the underlying genetic mechanisms are rarely known. Here we explore a recently identified "redness gene", CYP2J19, that is highly interesting in this context since it encodes a carotenoid-modifying enzyme (a C4 ketolase involved in both colour signalling and colour discrimination in the red (long wavelength) spectral region.)

Results: A single full-length CYP2J19 was retrieved from 43 species out of 70 avian genomes examined, representing all major avian clades. In addition, CYP2J19 sequences from 13 species of weaverbirds (Ploceidae), seven of which have red C4-ketocarotenoid coloration were analysed. Despite the conserved retinal function and pleiotropy of CYP2J19, analyses indicate that the gene has been positively selected throughout the radiation of birds, including sites within functional domains described in related CYP (cytochrome P450) loci. Analyses of eight further CYP loci across 25 species show that positive selection is common in this gene family in birds. There was no evidence for a change in selection pressure on CYP2J19 following co-option for red coloration in the weaverbirds.

Conclusions: The results presented here are consistent with an ancestral conserved function of CYP2J19 in the pigmentation of red retinal oil droplets used for colour vision, and its subsequent co-option for red integumentary coloration. The cause of positive selection on CYP2J19 is unclear, but may be partly related to compensatory mutations related to selection at the adjacent gene CYP2J40.
\end{abstract}

Keywords: CYP2J19, CYP, Red carotenoid coloration, Retinal oil droplets, Birds, Selection analysis, Pleiotropy

\section{Background}

Bright colours and other exaggerated visual and acoustic displays are usually attributed to antagonistic coevolution between senders and receivers, but the genetic control of both signalling and perception are poorly known. Recently, however, a potentially widely important genetic link was found in birds between the generation and sensory discrimination of long wavelength (yellow to red) carotenoid colour hues, which are frequent targets of social and sexual selection [1-7]. Red C4-ketocarotenoid pigmentation, the main mechanism for redness in birds,

\footnotetext{
* Correspondence: nim21@cam.ac.uk

'Department of Zoology, University of Cambridge, Cambridge CB2 3EJ, UK Full list of author information is available at the end of the article
}

was shown (in zebra finch and a hybrid canary) to depend on the gene CYP2J19, a member of the cytochrome P450 family of monooxygenases, which likely encodes an enzyme that catalyses the conversion of dietary yellow carotenoids into their red coloured derivatives $[8,9]$.

In addition to its function in coloration in some lineages, CYP2J19 appears to be widely expressed in the avian retina $[9,10]$, where it is involved in colour vision by generating the C4-ketocarotenoid astaxanthin in the red oil droplets of longwave-sensitive cones [10, 11]. Like other single cone oil droplets, these act as cut-off filters that shift and narrow the bandwidths of the cone absorption spectra, predicted to lead to enhanced colour constancy and finer colour discrimination [12], in this 
case in the red (long wavelength) spectral region. Hence the same gene appears to function in both the generation and the detection of red colour signals. A study on the evolutionary history of CYP2J19 in reptiles showed that it arose in the common ancestor of turtles and archosaurs [13]. The ancestral function of the gene was likely for retinal oil droplet pigmentation, with its function in red coloration being subsequently co-opted in certain avian and turtle lineages [13]. In birds, CYP2J19 was until recently only reported in some passerines, galliforms, ostriches and cormorants [8, 9, 13-15], but given that almost all bird species have red cone oil droplets, with the exception of a few lineages such as penguins and some owls [16, 17] it is predicted that CYP2J19 should be present and functional in most avian species. Indeed, a recent survey of avian genomes concluded that CYP2J19 is intact in all studied taxa except certain (and notably some nocturnal) avian lineages, where it is pseudogenised [18]. Whereas most of the few birds examined to date seem to have a single CYP2J19 gene, two copies have been reported in the zebra finch, one specialised for colour vision (CYP2J19A) and the other for red coloration (CYP2J19B) [8]. Given the importance of duplication events for functional divergence, it is an interesting question if and where CYP1J19 duplication has occurred in other bird lineages.

Carotenoid-based coloration (yellow, orange, red) has evolved multiple times in birds in a complex pattern [19] and, within a few avian clades, the evolution of red carotenoid colour hues has been studied, notably in the genus of African widowbirds and bishops (Ploceidae; Euplectes) together with its sister group including the genera Quelea and Foudia [20]. In this clade, red C4ketocarotenoid coloration evolved twice from a yellow ancestor, and is strongly associated with high hepatic (liver) expression of CYP2J19, whereas both yellow and red species express CYP2J19 in the retina [21]. Moreover, in contrast to the zebra finch, CYP2J19 occurs in a single copy in all Ploceidae studied so far [21]. Hence this is an excellent group in which to address whether the evolution of pleiotropy in CYP2J19 through the acquisition of CYP2J19-based red coloration is associated with a change in the pattern of selection on CYP2J19.

CYP2J19 is one member of the large family of CYP genes in birds that encode cytochrome P450 enzymes $[14,15]$. In order to interpret the molecular evolution of CYP2J19 we study additional CYP loci in multiple avian genomes, including CYP2J40, a gene of unknown function that lies adjacent to CYP2J19 on chromosome 8 [8]. Previous studies on the CYP2 family in birds have shown that positive selection is common in this family [22], but this study did not include CYP2J19.

The detection of selection in the genome, through the ratio of the rate of non-synonymous to synonymous mutations $(\mathrm{dN} / \mathrm{dS})$, is a powerful tool for identifying loci involved in adaptation [23], as illustrated by many compelling cases of the genetics of adaptation [24-26]. Directional selection towards a novel adaptive peak is the most common scenario invoked to explain a signature of selection at the molecular level. There is, however, another possibility, whereby the adaptive peak has already been reached but mildly deleterious alleles are still spreading through a variety of mechanisms, which leads to reduced fitness and selection for compensatory mutations that restore protein function [27]. In this scenario, positive selection is required to retain a steady state of optimal protein function. This can potentially explain how positive selection occurs in a gene with a conserved function, which might otherwise be expected to be evolving solely under purifying selection. Currently, however, there is a poor understanding of the prevalence of compensatory mutations.

In this study, we investigated the evolution of CYP2J19 in birds, by conducting a broad analysis of avian genomes for presence, copy number and selection of CYP2J19 with comparison to other CYP loci, and a focussed analysis of selection on CYP2J19 in the weaverbirds (Ploceidae), which vary in yellow and red carotenoid coloration. More specifically, we asked (i) whether CYP2J19 is present in all birds, (ii) what the copy number of CYP2J19 is in different avian lineages, (iii) what the pattern of selection on CYP2J19 across available avian genomes and how this compares to other $C Y P$ s, including CYP2J40, and (iv) whether selection on CYP2J19 changes after it was co-opted for a pleiotropic effect on red coloration in weaverbirds.

\section{Methods}

\section{Sequence acquisition}

BLASTn searches were performed on 70 avian genomes in Genbank using zebra finch and chicken CYP2J19 annotated in Ensembl 83 as query sequences [28]. The 9 exons of CYP2J19 were blast searched individually against the 70 genomes and the resultant sequences were examined for complete open reading frames. Fulllength (1431 bp) sequences of CYP2J19 from 43 species were retained for downstream analyses (Additional file 1: Table S1). It is of interest to note that only a few of the 70 species sampled have red coloration, and only the zebra finch and American flamingo have confirmed red coloration due to ketocarotenoids.

An assembled dataset of other CYPs was used in a matched comparative study of CYP evolution (Additional file 1: Table S1). The 43 avian genomes with full-length CYP2J19 were searched for 35 CYPs identified from the chicken genome, with the aim of obtaining complete data from the maximum number of $C Y P$ s and lineages. Orthologues from eight further full-length 
CYPs were obtained from 25 avian genomes, representing all major avian clades (Table 1). The full list of nine CYPs, their chromosomal locations in zebra finch, and length of ORF (open reading frame) is as follows: CYP2J19 (Chromosome 8, 1431 bp), CYP2J40 (Chromosome 8, $1482 \mathrm{bp}$ ), CYP19A1 (Chromosome 10, $1506 \mathrm{bp}$ ), CYP7A1 (Chromosome 2, $1536 \mathrm{bp}$ ), CYP8B1 (Chromosome 2, $1524 \mathrm{bp})$, CYP4V2 (Chromosome 4, $1548 \mathrm{bp}$ ), CYP3A9 (Chromosome 14, 1449 bp), CYP7B1 (Chromosome 2, 1404 bp), CYP20A1 (Chromosome 7, 1317 bp). We also examined whether the close synteny of CYP2J19 and CYP2J40 on chromosome 8 in the zebra finch is conserved in other avian genomes.

Full-length CYP2J19 sequences from thirteen species of Ploceidae were used to investigate selection in relation to coloration in this clade (species with C4ketocarotenoid coloration marked with an asterisk): Euplectes afer, "E. ardens, E. axillaris, "E. hordeaceus, E. macroura, "E. nigroventris, "E. orix, "Foudia madagascariensis, Ploceus capensis, P. melanocephalus, P. velatus, "Quelea erythrops, "Q. quelea, [19]. C4-ketocarotenoid coloration evolved independently in two clades of red ploceids: the Foudia/Quelea clade and the E. orix/hordeaceus/nigroventris/ardens clade [20]. The Genbank Accession numbers for all sequences used are shown in Additional file 1: Table S1.

All gene sequences were aligned in MEGA 6 [29] using MUSCLE [30]. Analyses were conducted using phylogenies obtained from BirdTree.org [31] (Additional file 2: Figures S1-S3), which combines information from multiple sources, and which for the ploceids studied here has the same topology as used in [20]. In order to check for effects of potential discordance between gene and species trees, phylogenetic reconstruction of CYP2J19 sequences was carried out on the 43 and 25 species dataset using maximum-likelihood in PhyML-SMS (Smart Model Selection) based on Bayesian information criterion (http:// www.atgc-montpellier.fr/phyml/). Evolutionary analyses were repeated for CYP2J19 using the reconstructed gene phylogeny.

\section{Molecular evolution analyses}

In order to investigate the presence and type of selective forces acting on CYP genes, the ratio of nonsynonymous to synonymous substitution rates $(\mathrm{dN} / \mathrm{d} S=\omega)$ was estimated using the CodeML program within PAML 4.7 [32]. Omega values less than one, equal to one, and more than one, correspond to negative, neutral and positive selection respectively. Several model comparisons were performed, including site, branch, clade and branch-site comparisons for detection of positive selection. Bonferroni correction for multiple testing was carried out in the comparative analysis of CYPs, with $n=9$ representing the number of loci tested. All models were run several times (where applicable) applying different initial $\omega$ values in order to avoid local likelihood peaks. Likelihood ratio tests (LRT) were used to test for significance between nested models. The Bayes empirical Bayes method (BEB) was used to identify positively selected sites when significant results were found.

Site models allow the $\omega$ to vary among different codon sites [33], and comparisons were made between M1a (Nearly Neutral model) and M2a (Positive selection), and also between M7 (beta) and M8 (beta\& $\omega$ ) models. Model M1a allows for sites to fall into two categories: $\omega$ $<1$ and $\omega=1$, whereas M2a includes an additional category of $\omega>1$. M7-M8 comparison models $\omega$ as a beta probability distribution. The M8 model has 11 site classes and includes an additional category of $\omega>1$ absent from M7. The critical Chi-square values for the LRT comparisons between M1a-M2a and M7-M8 were 5.99 at $5 \%$ and 9.21 at $1 \%$ under 2 degrees of freedom.

To the weaverbird CYP2J19 dataset, we applied branch-specific models in order to assess whether the $\omega$ values varied significantly between preselected foreground and background lineages with and without C4ketocarotenoid coloration [34]. Here, the null model (M0) assumes a single $\omega$ value across all branches. In addition, Clade model $\mathrm{C}(\mathrm{CmC})$ was applied to the weaverbird CYP2J19 dataset in order to investigate sitespecific differences in selection in relation to coloration [35]. Partitions were made based on the presence or absence of C4-ketocarotenoid coloration. Finally, branchsite models were implemented on the ploceid dataset. The modified alternative model A [36] was compared with the null model which fixes $\omega=1$.

\section{Results}

BLASTn searches identified CYP2J19-like sequences within all of the 70 avian genomes with the exception of the bald eagle (Haliaeetus leucocephalus) and the twobarred warbler (Phylloscopus plumbeitarsus). For five species, not all 9 exons of CYP2J19 were recovered (Amazona aestival, Amazona vittata, Apteryx australis, Ara macao, and Lyrurus tetrix), and a further 20 species were discarded due to the presence of premature stop codons. Full-length open reading frames of CYP2J19 were obtained for the remaining 43 species, and, apart from the zebra finch, there was no evidence for duplicate copies in any of them. The synteny of CYP2J19 and CYP2J40 on chromosome 8 is strongly conserved in birds, and the loci were within $4 \mathrm{~kb}$ of each other in all cases with sufficiently long contigs (Additional file 3: Table S3).

Analysis of full-length coding sequence of CYP2J19 in 43 species revealed significant evidence for positive selection ( $>6 \%$ positively selected sites with $\omega>1.3$; LRS $>$ 61.57, $p<0.01$ ) under M7-M8 comparisons (Table 2). 
Table 170 avian genomes investigated in the study and those used in downstream analyses

\begin{tabular}{|c|c|c|c|}
\hline Order & 70 avian genomes searched & 43 species with full-length CYP2J19 & $\begin{array}{l}25 \text { species used in } \\
\text { comparative CYP analysis }\end{array}$ \\
\hline Struthioniformes & Struthio camelus (African ostrich) & $\checkmark$ & \\
\hline Apterygiformes & Apteryx australis (brown kiwi) & & \\
\hline Tinamiformes & Tinamus guttatus (white-throated tinamou) & & \\
\hline \multirow[t]{5}{*}{ Galliformes } & Colinus virginianus (northern bobwhite) & & \\
\hline & Coturnix japonica (Japanese quail) & & \\
\hline & Gallus gallus (red junglefowl) & $\checkmark$ & $\checkmark$ \\
\hline & Lyrurus tetrix (black grouse) & & \\
\hline & Meleagris gallopavo (turkey) & & \\
\hline \multirow[t]{2}{*}{ Anseriformes } & Anas platyrhynchos (mallard) & $\checkmark$ & $\checkmark$ \\
\hline & Anser cygnoides (swan goose) & $\checkmark$ & $\checkmark$ \\
\hline Phoenicopteriformes & Phoenicopterus ruber (American flamingo) & & \\
\hline Podicipediformes & Podiceps cristatus (great-crested grebe) & & \\
\hline Columbiformes & Columba livia (rock pigeon) & $\checkmark$ & $\checkmark$ \\
\hline Mesitornithiformes & Mesitornis unicolor (brown roatelo) & $\checkmark$ & \\
\hline Pteroclidiformes & Pterocles gutturalis (yellow-throated sandgrouse) & & \\
\hline \multirow[t]{2}{*}{ Apodiformes } & Calypte anna (Anna's hummingbird) & $\checkmark$ & \\
\hline & Chaetura pelagica (chimney swift) & $\checkmark$ & $\checkmark$ \\
\hline Caprimulgiformes & Caprimulgus carolinensis (chuck-will's-widow) & $\checkmark$ & \\
\hline Cuculiformes & Cuculus canorus (common cuckoo) & $\checkmark$ & $\checkmark$ \\
\hline \multirow[t]{2}{*}{ Otidiformes } & Chlamydotis macqueenii (MacQueen's bustard) & & \\
\hline & Chlamydotis undulata (houbara bustard) & & \\
\hline Musophagiformes & Tauraco erythrolophus (red-crested turaco) & $\checkmark$ & \\
\hline Opisthocomiformes & Opisthocomus hoazin (hoatzin) & $\checkmark$ & $\checkmark$ \\
\hline \multirow[t]{2}{*}{ Gruiformes } & Balearica pavonina (black crowned crane) & & \\
\hline & Balearica regulorum (grey crowned crane) & $\checkmark$ & $\checkmark$ \\
\hline \multirow[t]{2}{*}{ Charadriiformes } & Calidris pugnax (ruff) & & \\
\hline & Charadrius vociferous (killdeer) & $\checkmark$ & \\
\hline Gaviiformes & Gavia stellate (red-throated loon) & & \\
\hline Procellariiformes & Fulmarus glacialis (northern fulmar) & $\checkmark$ & $\checkmark$ \\
\hline \multirow[t]{2}{*}{ Sphenisciformes } & Aptenodytes forsteri (emperor penguin) & $\checkmark$ & $\checkmark$ \\
\hline & Pygoscelis adeliae (Adelie penguin) & & \\
\hline Suliformes & Phalacrocorax carbo (great cormorant) & & \\
\hline \multirow[t]{3}{*}{ Pelecaniformes } & Egretta garzetta (little egret) & $\checkmark$ & \\
\hline & Nipponia nippon (crested ibis) & $\checkmark$ & $\checkmark$ \\
\hline & Pelecanus crispus (Dalmatian pelican) & & \\
\hline Eurypygiformes & Eurypyga helias (sunbittern) & & \\
\hline Phaethontiformes & Phaethon lepturus (white-tailed tropicbird) & $\checkmark$ & $\checkmark$ \\
\hline Cathartiformes & Cathartes aura (turkey vulture) & & \\
\hline \multirow[t]{2}{*}{ Accipitriformes } & Haliaeetus albicilla (white-tailed eagle) & $\checkmark$ & $\checkmark$ \\
\hline & Haliaeetus leucocephalus (bald eagle) & & \\
\hline
\end{tabular}


Table 170 avian genomes investigated in the study and those used in downstream analyses (Continued)

\begin{tabular}{|c|c|c|c|}
\hline Order & 70 avian genomes searched & 43 species with full-length CYP2J19 & $\begin{array}{l}25 \text { species used in } \\
\text { comparative CYP analysis }\end{array}$ \\
\hline & Aquila chrysaetos (golden eagle) & $\checkmark$ & $\checkmark$ \\
\hline Strigiformes & Tyto alba (barn owl) & & \\
\hline Coliiformes & Colius striatus (speckled mousebird) & $\checkmark$ & $\checkmark$ \\
\hline Leptosomiformes & Leptosomus discolour (cuckoo roller) & $\checkmark$ & \\
\hline Trogoniformes & Apaloderma vittatum (bar-tailed trogon) & $\checkmark$ & \\
\hline Bucerotiformes & Buceros rhinoceros (rhinoceros hornbill) & $\checkmark$ & \\
\hline Coraciiformes & Merops nubicus (northern carmine bee-eater) & & \\
\hline Piciformes & Picoides pubescens (downy woodpecker) & $\checkmark$ & $\checkmark$ \\
\hline Cariamiformes & Cariama cristata (red-legged seriema) & $\checkmark$ & \\
\hline \multirow[t]{2}{*}{ Falconiformes } & Falco cherrug (saker falcon) & $\checkmark$ & $\checkmark$ \\
\hline & Falco peregrinus (peregrine falcon) & $\checkmark$ & $\checkmark$ \\
\hline \multirow[t]{5}{*}{ Psittaciformes } & Amazona aestiva (blue-fronted amazon) & & \\
\hline & Amazona vittata (Puerto Rican parrot) & & \\
\hline & Ara macao (scarlet macaw) & & \\
\hline & Melopsittacus undulatus (budgerigar) & $\checkmark$ & $\checkmark$ \\
\hline & Nestor notabilis (kea) & $\checkmark$ & \\
\hline \multirow[t]{14}{*}{ Passeriformes } & Acanthisitta chloris (rifleman) & $\checkmark$ & \\
\hline & Corvus brachyrhynchos (American crow) & & \\
\hline & Corvus cornix (hooded crow) & $\checkmark$ & $\checkmark$ \\
\hline & Ficedula albicollis (collared flycatcher) & $\checkmark$ & $\checkmark$ \\
\hline & Geospiza fortis (medium ground-finch) & $\checkmark$ & $\checkmark$ \\
\hline & Manacus vitellinus (golden-collared manakin) & $\checkmark$ & \\
\hline & Parus major (great tit) & $\checkmark$ & \\
\hline & Phylloscopus plumbeitarsus (two-barred warbler) & & \\
\hline & Pseudopodoces humilis (Tibetan ground-tit) & $\checkmark$ & $\checkmark$ \\
\hline & Serinus canaria (common canary) & $\checkmark$ & $\checkmark$ \\
\hline & Sturnus vulgaris (common starling) & $\checkmark$ & \\
\hline & Taeniopygia guttata (zebra finch) & $\checkmark$ & $\checkmark$ \\
\hline & Zonotrichia albicollis (white-throated sparrow) & $\checkmark$ & \\
\hline & Zosterops lateralis (silver-eye) & $\checkmark$ & \\
\hline
\end{tabular}

Table 2 Site-specific analysis of CYP2J19 for 43 avian species in PAML

\begin{tabular}{|c|c|c|c|c|c|c|c|}
\hline Model & Parameter estimates & $\ln L$ & Model comparison & LRT Statistic & $d f$ & $P$-value & $\begin{array}{l}\text { Positively selected sites under } \\
\text { BEB P > 95\% (bold: } P>99 \%)\end{array}$ \\
\hline Mo & $\omega_{0}=0.147$ & $-12,990.709$ & & & & & \\
\hline M1a & $\begin{array}{l}\omega_{0}=0.056 p_{0}=0.868 \\
\omega_{1}=1.000 p_{1}=0.132\end{array}$ & $-12,561.580$ & & & & & \\
\hline $\mathrm{M} 2 \mathrm{a}$ & $\begin{array}{l}\omega_{0}=0.056 p_{0}=0.868 \\
\omega_{1}=1.000 p_{1}=0.077 \\
\omega_{2}=1.000 p_{2}=0.055\end{array}$ & $-12,561.580$ & M1a vs. M2a & 0.000 & 2 & 1.000 & \\
\hline M7 & $p=0.168 q=0.788$ & $-12,533.632$ & & & & & \\
\hline M8 & $\begin{array}{l}p_{0}=0.935\left(p_{1}=0.065\right) \\
p=0.302 q=2.898 \\
\omega_{s}=1.383\end{array}$ & $-12,502.845$ & M7 vs. M8 & 61.574 & 2 & $0.000^{*}$ & $\underline{37}, \underline{122}, 329, \mathbf{4 5 5}, \underline{\mathbf{4 7 4}}$ \\
\hline
\end{tabular}

Underlined sites fall within predicted functional domains for CYP2 proteins annotated in Almeida et al. 2016 [22] 
Five positively selected sites were identified by $\mathrm{BEB}$, and alignment of CYP2J19 with other avian CYP2 protein sequences described in Almeida et al. (2016) [22] showed that three of the sites $(37,122,474)$ were located within predicted functional domains: Substrate Recognition Site 0 (SRS0, site 37), Heme binding domain (HEM, site 122) and Substrate Recognition Site 6 (SRS6, site 474). No evidence for positive selection was found under M1aM2a tests (Table 2). Similar analyses using the CYP2J19 gene phylogeny revealed similar results, with significant evidence of positive selection under M7M8 (Additional file 4: Table S2).

Given the evidence for positive selection on CYP2J19, comparisons were made with other $C Y P$ loci. Using genomic searches, full sequences were obtained for a further eight CYP genes across 25 species of birds which are a subset of the 43 species with full CYP2J19 ORFs (Table 1). Analyses revealed that six of the nine CYPS (CYP2J19, CYP7B1, CYP2J40, CYP8B1,CYP4V2 and CYP3A9) were under significant positive site-specific selection in comparisons between M7 - M8 models, with 0.02-0.10 sites with an $\omega$ of 1.39-2.60. Of these, four CYPs (CYP2J40, CYP8B1, CYP4V2 and CYP3A9) also showed significant site-specific selection in M1a-M2a model comparisons (Table 3).

Amino acid alignment of translated CYP2J19 with annotated structures of CYP2 proteins showed that certain positively selected sites, identified by BEB, fall within functional domains: SRS0 (site 37) [22] and SRS-3 (site 233) [37], while positively selected sites in CYP2J40 lie in SRSO (sites 56, 59, 60, 61 and 80) and SRS-3 (sites 247, 250).

There was no evidence for positive selection on CYP2J19 within the Ploceidae (Table 4). Neither was there a significant difference in $\omega$ between lineages with and those without C4-ketocarotenoid-based red coloration, either in branch models or clade models, although there was a tendency for the lineages with red C4ketocarotenoid coloration to have a higher overall $\omega$ (Table 4). There was no indication of positive selection when applying branch-site models to lineages with red C4-ketocarotenoid coloration (Table 4).

\section{Discussion}

A single copy of CYP2J19 was identified in a phylogenetically broad range of avian lineages, supporting a single CYP2J19 gene as the ancestral avian state. Considering that red C4-ketocarotenoid coloration has a patchy distribution in birds (including the lineages sampled here), whereas red retinal oil droplets are present in almost all birds examined, the contribution to colour vision is the ancestral and likely strongly conserved function of CYP2J19. The finding of positive rather than purifying selection on CYP2J19 across all lineages analysed is thus somewhat surprising. There was no evidence that the acquisition of a second, likely sexually-selected, function in red coloration affected the selective pressure on CYP2J19. However, there was evidence for positive selection on CYP2J40, a syntenic gene to CYP2J19 of unknown function, which may plausibly lead to the evolution of compensatory mutations in CYP2J19.

In most avian species examined, there was evidence for the presence of CYP2J19. This concords with a recent independent study on the evolution of CYP2J19 in birds [18]. Although full-length open reading frames were only retrieved for $43 / 70$ (61\%) of species, these 43 species span most major avian lineages and it seems likely that poor genome quality can account for much of the missing data. Species without a full length CYP2J19 ORF in our study include the barn owl and the southern brown kiwi that were identified in [16] based on retinal transcriptome data as likely true pseudogenization events reflecting a nocturnal lifestyle. Of the 43 species with intact ORFs, only the zebra finch (Taeniopygia guttata) has been confirmed to possess red C4ketocarotenoid based coloration [1,38]. By contrast, it is thought that almost all birds have red oil droplets in their retinas, including some nocturnal lineages such as the tawny owl [39]. Hence, the results presented here support the notion that CYP2J19 has an ancestral, conserved function in avian colour vision and its function in red coloration appears to have been independently gained along specific bird lineages. This would most likely have been through changes in the patterns of expression of CYP2J19 as a result of in cis-regulatory sequences and/or trans-acting factors. This concords with previous findings investigating the origin of CYP2J19 in the reptiles [13].

Analyses of the 43 species dataset as well as the reduced 25 species dataset consistently revealed that positive selection acted on CYP2J19 throughout its evolution in birds. In particular, site-specific selection was found to act within the newly defined substrate recognition site (SRS0) of CYP2J19 for both datasets [22]. This is a novel finding and somewhat surprising given the inferred conserved function of CYP2J19 in the retina, where it is involved in generating the C4-ketocarotenoid astaxanthin that is the major component of all red cone oil droplets examined [10]. The co-option of CYP2J19 for a function in red coloration might provide a further constraint on CYP2J19 evolution, or alternatively might necessitate adjustments for this second function. However, no evidence was found for a change in mode of selection on CYP2J19 in ploceids, where a direct comparison can be made between lineages with exaggerated red C4ketocarotenoid coloration and those without.

Extending the analyses to eight other CYP loci showed that selection is common in the gene family. Five of the 


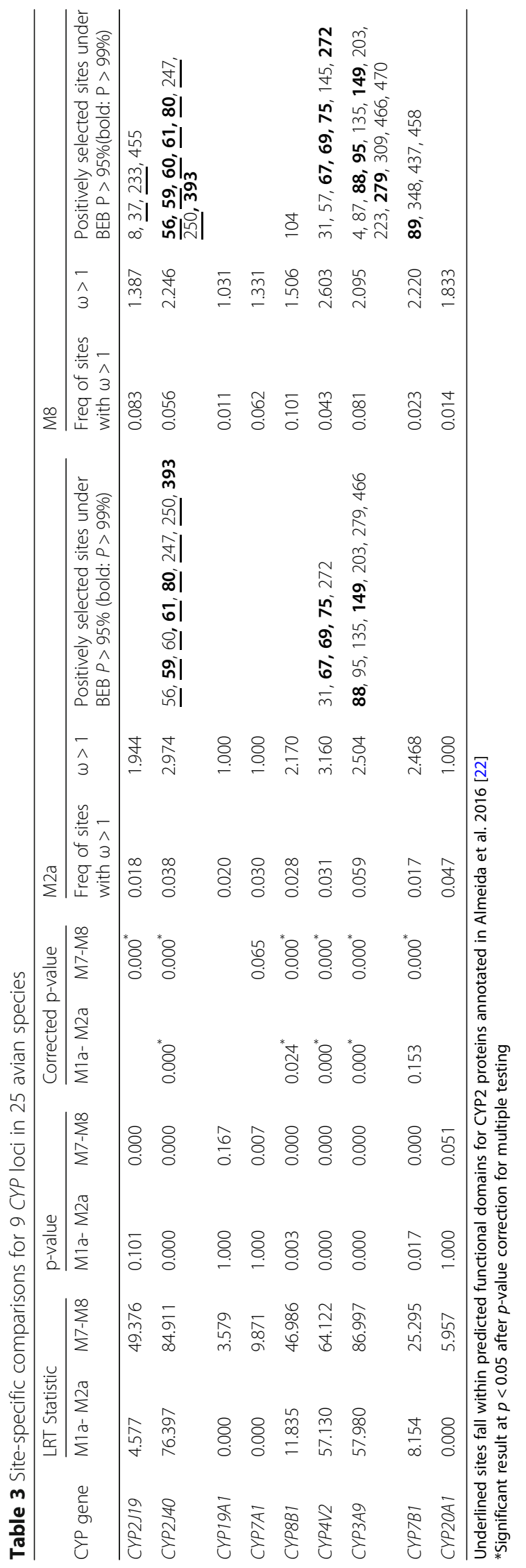


Table 4 Summary of PAML results for CYP2J19 across 13 ploceid species including site-specific, clade ("CmC"), branch and branch-site analyses

\begin{tabular}{|c|c|c|c|c|c|c|c|c|c|c|}
\hline Model & \multicolumn{5}{|c|}{ Parameter estimates } & $\ln L$ & Model comparison & LRT Statistic & $\mathrm{df}$ & $p$-value \\
\hline $\mathrm{MO}$ & \multicolumn{5}{|l|}{$\omega_{0}=0.241$} & -2591.727 & & & & \\
\hline \multirow[t]{2}{*}{ M1a } & \multicolumn{5}{|c|}{$\omega_{0}=0.024 p_{0}=0.782$} & & & & & \\
\hline & \multicolumn{5}{|c|}{$\omega_{1}=1.000 p_{1}=0.218$} & -2587.623 & & & & \\
\hline \multirow[t]{2}{*}{$\mathrm{M} 2 \mathrm{a}$} & \multicolumn{5}{|c|}{$\omega_{0}=0.176 p_{0}=0.985$} & & & & & \\
\hline & \multicolumn{5}{|c|}{$\begin{array}{l}\omega_{1}=1.000 p_{1}=0.000 \\
\omega_{2}=5.935 p_{2}=0.015\end{array}$} & -2586.444 & M1a vs. M2a & 2.358 & 2 & 0.308 \\
\hline M7 & \multicolumn{5}{|c|}{$p=0.005 q=0.019$} & -2587.657 & & & & \\
\hline \multirow[t]{2}{*}{ M8 } & \multicolumn{5}{|c|}{$p_{0}=0.985\left(p_{1}=0.015\right)$} & & & & & \\
\hline & \multicolumn{5}{|c|}{$\begin{array}{l}p=21.271 q=99.000 \\
\omega_{s}=5.960\end{array}$} & -2586.447 & M7 vs. M8 & 2.422 & 2 & 0.298 \\
\hline M2a_rel ${ }^{a}$ & \multicolumn{5}{|c|}{$\begin{array}{l}\omega_{0}=0.176 p_{0}=0.985 \\
\omega_{1}=1.000 p_{1}=0.000 \\
\omega_{2}=5.935 p_{2}=0.015\end{array}$} & -2586.444 & & & & \\
\hline $\mathrm{CmC}^{\mathrm{a}}$ & \multicolumn{5}{|c|}{$\begin{array}{l}\omega_{0}=0.091 p_{0}=0.913 \\
\omega_{1}=1.000 p_{1}=0.000 \\
\omega_{2}(\# 0)=1.101 p_{2}=0.087 \\
\omega_{2}(\# 1)=3.393\end{array}$} & -2585.570 & M2a_rel vs. $\mathrm{CmC}$ & 1.749 & 1 & 0.186 \\
\hline \multirow[t]{2}{*}{$2 \omega$ branch model $^{a}$} & \multicolumn{5}{|l|}{$\omega(\# 0)=0.165$} & & & & & \\
\hline & \multicolumn{5}{|l|}{$\omega(\# 1)=0.370$} & -2590.044 & M0 vs. $2 \omega$ branch model & 3.366 & 1 & 0.067 \\
\hline \multirow[t]{4}{*}{ Branch-site Null $^{a}$} & site class & 0 & 1 & $2 a$ & $2 b$ & -2586.422 & & & & \\
\hline & proportion & 0.677 & 0.144 & 0.148 & 0.031 & & & & & \\
\hline & background $\omega$ & 0.000 & 1.000 & 0.000 & 1.000 & & & & & \\
\hline & foreground $\omega$ & 0.000 & 1.000 & 1.000 & 1.000 & & & & & \\
\hline \multirow[t]{4}{*}{ Branch-site Alternative Model $\mathrm{A}^{\mathrm{a}}$} & site class & 0 & 1 & $2 a$ & $2 b$ & -2586.295 & Null vs. Alternative Model A & 0.255 & 1 & 0.613 \\
\hline & proportion & 0.756 & 0.147 & 0.081 & 0.016 & & & & & \\
\hline & background $\omega$ & 0.012 & 1.000 & 0.012 & 1.000 & & & & & \\
\hline & foreground $\omega$ & 0.012 & 1.000 & 1.939 & 1.939 & & & & & \\
\hline
\end{tabular}

${ }^{\mathrm{a} B r a n c h}$ partitions for Clade model C, Branch and Branch-site models: \#1 = the two clades containing ketocarotenoid species: (E. orix, E. hordeaceus, E. nigroventris and E. ardens) and (F. madagascariensis, Q. erythrops and Q. quelea); \#0 = all other lineages

loci showed evidence for positive selection and these included genes that have been shown in mammals to be involved in bile acid synthesis (oxysterol $7 \alpha$-hydroxylase (CYP7B1) and sterol 12 $\alpha$-hydroxylase (CYP8B1)) [40-43], fatty-acid oxidation (fatty acid $\omega$-hydroxylase, CYP4V2) [44] and control of sexual dimorphism (CYP3A9) [45-48]. The remaining gene under positive selection is CYP2J40, of unknown function. This gene is of particular interest since it lies adjacent to CYP2J19 on chromosome eight in zebra finch. It has one of the strongest signatures of positive selection among the loci studied, and, consistent with previous results (where the gene is named CYP2J_2 [22]), several positively selected sites lie in the functional domain SRSO. The three CYP loci found not to be under positive selection are: the aromatase, CYP19A1, which plays a crucial role in sex determination, female receptivity and social interactions, and appears to be well conserved in nearly all species studied [49-53]; CYP7A1, which catalyses the first step in bile acid synthesis [54, 55]; and CYP20A1, of unknown function.
Overall, therefore, although certain loci with wellconserved functions (notably CYP19A1) do not show evidence of positive selection, there are many $C Y P$ loci which do show evidence of positive selection across a broad phylogenetic sampling of birds. Moreover, the sample of 9 CYP loci are likely among the most conserved in the avian genome since only identifiable $C Y P$ genes were targeted in diverse genomes. A study focusing on the CYP2 gene family, which is believed to primarily be involved in metabolising toxins, also found evidence for widespread positive selection (6 out of 12 CYP2 subfamilies, and 11 out of 17 loci; Almeida et al. 2016 [22]). The results presented here are thus not unusual for CYP loci in general, but while the selection of many of them may be attributed to coevolution with e.g. new toxins, the question remains why some $C Y P$ loci with more conserved functions, such as CYP2J19, are also evolving under positive selection. For CYP2J19, an intriguing possibility is that it is affected by selection acting on CYP2J40, which is within $4 \mathrm{~kb}$ of CYP2J40 on 
chromosome 8 in all lineages for which there is sufficient genomic information (Additional file 3). Specifically, it could be that directional selection on CYP2J40 sometimes leads to fixation of linked mildly deleterious alleles at CYP2J19 that are then followed by positive selection for compensatory mutations. Establishing the function of CYP2J40 would be helpful in assessing this.

\section{Conclusion}

To conclude, a single copy of CYP2J19 was found to be widespread across avian lineages, which is consistent with a conserved ancestral function in colour vision and subsequent co-option for red integumentary coloration. Like several other $C Y P$ loci, including some with conserved functions, CYP2J19 shows evidence of evolving under positive selection across birds. The cause of the positive selection on CYP2J19 is unclear. There is no evidence for a change in selection pressure on CYP2J19 following co-option for red coloration, but one factor may be compensatory mutations related to selection at the adjacent gene CYP2J40.

\section{Additional files}

\section{Additional file 1: Accession numbers of sequences studied. (DOCX $58 \mathrm{~kb}$ ) \\ Additional file 2: Species phylogenies used for PAML analyses.} (DOCX $94 \mathrm{~kb}$ )

Additional file 3: Intergenic distances between CYP2J19 and CYP2J40 in avian genomes. (DOCX $54 \mathrm{~kb}$ )

Additional file 4: Results for analysis of selection on CYP2J19 using gene tree versus species tree. (DOCX $19 \mathrm{~kb}$ )

\section{Abbreviations}

BEB: Bayes empirical Bayes; CYP: Gene encoding a cytochrome P450 enzyme; $\mathrm{dN}$ : Rate of non-synonymous substitution; dS: Rate of synonymous substitution; HEM: Heme binding domain; LRT: Likelihood ratio test; ORF: Open reading frame; SRS: Substrate recognition domain

\section{Acknowledgements}

We thank two anonymous reviewers for helpful comments on the manuscript.

\section{Funding}

We thank the BBSRC (to HT), Swedish Research Council (to SA) and Murray Edwards College (to NM) for funding. The funding bodies played no role in study design, analysis, or preparation of the manuscript.

\section{Availability of data and materials}

The data analysed in this study are available on Genbank: https:// www.ncbi.nlm.nih.gov/genbank/. See Additional file 1: Table S1 for Accession numbers.

\section{Authors' contributions}

HT designed and carried out all sequence data collection and selection analysis, and helped draft the manuscript; SA supplied the samples and helped draft and edit the manuscript; NM conceived the study, designed, drafted and edited the manuscript. All authors gave final approval for publication.

\section{Ethics approval and consent to participate} Not applicable.
Consent for publication

Not applicable.

\section{Competing interests}

The authors declare that they have no competing interests.

\section{Publisher's Note}

Springer Nature remains neutral with regard to jurisdictional claims in published maps and institutional affiliations.

\section{Author details}

${ }^{1}$ Department of Zoology, University of Cambridge, Cambridge CB2 3EJ, UK. ${ }^{2}$ Department of Biological and Environmental Sciences, University of Gothenburg, 40530 Göteborg, Sweden.

Received: 26 July 2017 Accepted: 31 January 2018

Published online: 13 February 2018

References

1. Burley N, Coopersmith CB. Bill Color preferences of zebra finches. Ethology. 1987;76:133-51.

2. Hill GE. Female house finches prefer colorful males - sexual selection for a condition-dependent trait. Anim Behav. 1990;40:563-72.

3. Pryke SR, Andersson S, Lawes MJ, Piper SE. Carotenoid status signaling in captive and wild red-collared widowbirds: independent effects of badge size and color. Behav Ecol. 2002;13:622-31.

4. Ninnes CE, Webb SL, Andersson S. Are red bishops red enough? On the persistence of a generalized receiver bias in Euplectes. Behav Ecol. 2017;28: 117-22.

5. Hill GE, McGraw KJ. Bird coloration. 1st vol. Harvard University Press; 2006

6. Gray DA. Carotenoids and sexual dichromatism in north american passerine birds. Am Nat. 1996:148:453-80.

7. Santos ESA, Scheck D, Nakagawa S. Dominance and plumage traits: metaanalysis and metaregression analysis. Anim Behav. 2011;82:3-19.

8. Mundy NI, Stapley J, Bennison C, Tucker R, Twyman H, Kim KW, Burke T, Birkhead TR, Andersson S, Slate J. Red carotenoid coloration in the zebra finch is controlled by a cytochrome P450 gene cluster. Curr Biol. 2016;26: 1435-40.

9. Lopes RJ, Johnson JD, Toomey MB, Ferreira MS, Araujo PM, Melo-Ferreira J, Andersson L, Hill GE, Corbo JC, Carneiro M. Genetic basis for red coloration in birds. Curr Biol. 2016;26:1427-34

10. Goldsmith $\mathrm{TH}$, Collins JS, Licht S. The cone oil droplets of avian retinas. Vis Res. 1984:24:1661-71.

11. Toomey MB, Collins AM, Frederiksen R, Cornwall MC, Timlin JA, Corbo JC. A complex carotenoid palette tunes avian colour vision. J R Soc Interface. 2015;12

12. Vorobyev M. Coloured oil droplets enhance colour discrimination. Proc R Soc B. 2003;270:1255-61

13. Twyman H, Valenzuela N, Literman R, Andersson S, Mundy NI. Seeing red to being red: conserved genetic mechanism for red cone oil droplets and cooption for red coloration in birds and turtles. Proc R Soc B. 2016;283

14. Watanabe KP, Kawai YK, Ikenaka Y, Kawata M, Ikushiro S-I, Sakaki T, Ishizuka M. Avian cytochrome P450 (CYP) 1-3 family genes: isoforms, evolutionary relationships, and mrna expression in chicken liver. PLoS One. 2013:8: e75689.

15. Kubota A, Stegeman JJ, Goldstone JV, Nelson DR, Kim EY, Tanabe S, Iwata H. Cytochrome P450 CYP2 genes in the common cormorant: evolutionary relationships with 130 diapsid CYP2 clan sequences and chemical effects on their expression. Comp Biochem Physiol C Toxicol Pharmacol. 2011;153:280-9.

16. Gondo $\mathrm{M}$, Ando H. Comparative histophysiological study of oil droplets in the avian retina. Japanese Journal of Ornithology. 1995:44:81-91.

17. Bowmaker JK, Martin GR. Visual pigments and oil droplets in the penguin, spheniscus humboldti. J Comp Physiol A. 1985;156:71-7.

18. Emerling CA. Independent pseudogenization of CYP2J19 in penguins, owls and kiwis implicates gene in red carotenoid synthesis. Mol Phyl Evol. 2018; 118:47-53.

19. Thomas DB, McGraw KJ, Butler MW, Carrano MT, Madden O, James HF. Ancient origins and multiple appearances of carotenoid-pigmented feathers in birds. Proc R Soc B. 2014;281 
20. Prager M, Andersson S. Convergent evolution of red carotenoid coloration in widowbirds and bishops (Euplectes spp.). Evolution. 2010;64:3609-19.

21. Twyman H, Prager M, Mundy NI, Andersson S. Expression of a carotenoidmodifying gene and evolution of red coloration in weaverbirds (Ploceidae). Mol Ecol. 2018; https://doi.org/10.1111/mec.14451.

22. Almeida D, Maldonado E, Khan I, Silva L, Gilbert MTP, Zhang GJ, Jarvis ED, O'Brien SJ, Johnson WE, Antunes A. Whole-genome identification, phylogeny, and evolution of the cytochrome P450 family 2 (CYP2) subfamilies in birds. Genome Biol Evol. 2016;8:1115-31.

23. Yang Z, Bielawski JP. Statistical methods for detecting molecular adaptation. Trends Ecol Evolut. 2000;15:496-503.

24. Nadeau NJ, Burke T, Mundy NI. Evolution of an avian pigmentation gene correlates with a measure of sexual selection. Proc R Soc B. 2007;274:1807-13.

25. Hughes AL, Nei M. Pattern of nucleotide substitution at major histocompatibility complex class I loci reveals overdominant selection. Nature. 1988;335:167-70.

26. Messler W, Stewart CB. Episodic adaptive evolution of primate lysozymes. Nature. 1997;385:151-4.

27. Camps M, Herman A, Loh E, Loeb LA. Genetic constraints on protein evolution. Crit Rev Biochem Mol Biol. 2007:42:313-26.

28. Cunningham F, Amode MR, Barrell D, Beal K, Billis K, Brent S, Carvalho-Silva D, Clapham P, Coates G, Fitzgerald S, et al. Ensembl 2015. Nucleic Acids Res. 2015:43:D662-9.

29. Tamura K, Stecher G, Peterson D, Filipski A, Kumar S. MEGA6: molecular evolutionary genetics analysis version 6.0. Mol Biol Evol. 2013;30:2725-9.

30. Edgar RC. Muscle: multiple sequence alignment with high accuracy and high throughput. Nucleic Acids Res. 2004;32:1792-7.

31. Jetz W, Thomas GH, Joy JB, Hartmann K, Mooers AO. The global diversity of birds in space and time. Nature. 2012;491:444-8.

32. Yang Z. Paml 4: phylogenetic analysis by maximum likelihood. Mol Biol Evol. 2007;24:1586-91.

33. Yang Z. Paml: a program package for phylogenetic analysis by maximum likelihood. Comput Appl Biosci. 1997;13:555-6.

34. Yang Z. Likelihood ratio tests for detecting positive selection and application to primate lysozyme evolution. Mol Biol Evol. 1998;15:568-73.

35. Weadick CJ, Chang BSW. An improved likelihood ratio test for detecting site-specific functional divergence among clades of protein-coding genes. Mol Biol Evol. 2012;29:1297-300.

36. Zhang JZ, Nielsen R, Yang ZH. Evaluation of an improved branch-site likelihood method for detecting positive selection at the molecular level. Mol Biol Evol. 2005;22:2472-9.

37. Gotoh O. Substrate Recognition sites in cytochrome-P450 family-2 (CYP2) proteins inferred from comparative analyses of amino-acid and coding nucleotide-sequences. J Appl Biol Chem. 1992;267:83-90.

38. McGraw KJ, Toomey MB. Carotenoid accumulation in the tissues of zebra finches: predictors of integumentary pigmentation and implications for carotenoid allocation strategies. Physiol Biochem Zool. 2010;83:97-109.

39. Bowmaker JK, Martin GR. Visual pigments and color-vision in a nocturnal bird, Strix aluco (tawny owl). Vis Res. 1978;18:1125-30.

40. Rose KA, Stapleton G, Dott K, Kieny MP, Best R, Schwarz M, Russell DW, Bjorkhem I, Seckl J, Lathe R. Cyp7b, a novel brain cytochrome P450, catalyzes the synthesis of neurosteroids 7 alpha-hydroxy dehydroepiandrosterone and 7 alpha-hydroxy pregnenolone. PProc Natl Acad Sci U S A. 1997;94:4925-30.

41. Schwarz M, Lund EG, Lathe R, Björkhem I, Russell DW. Identification and characterization of a mouse oxysterol 7a-hydroxylase cDNA. J Biol Chem. 1997;272:23995-4001.

42. Eggertsen $\mathrm{G}$, Olin M, Andersson U, Ishida H, Kubota S, Hellman U, Okuda K-I, Björkhem I. Molecular cloning and expression of rabbit sterol 12ahydroxylase. J Biol Chem. 1996;271:32269-75.

43. Gafvels M, Olin M, Chowdhary BP, Raudsepp T, Andersson U, Persson B, Jansson M, Bjorkhem I, Eggertsen G. Structure and chromosomal assignment of the sterol 12 alpha-hydroxylase gene (CYP8B1) in human and mouse: eukaryotic cytochrome P450 gene devoid of introns. Genomics. 1999;56:184-96.

44. Nakano M, Kelly EJ, Rettie AE. Expression and characterization of CYP4V2 as a fatty acid omega-hydroxylase. Drug Metab Dispos. 2009;37:2119-22.

45. Mahnke Z, Strotkamp D, Roos PH, Hanstein WG, Chabot GG, Nef P. Expression and inducibility of cytochrome P450 3A9 (CYP3A9) and other members of the CYP3A subfamily in rat liver. Arch Biochem Biophys. 1997: 337:62-8.
46. Anakk S, Ku CY, Vore M, Strobel HW. Insights into gender bias: rat cytochrome P450 3A9. J Pharm Exp Ther. 2003;305:703-9.

47. Wang HM, Strobel HW. Regulation of CYP3A9 gene expression by estrogen and catalytic studies using cytochrome P4503A9 expressed in escherichia coli. Arch Biochem Biophys. 1997;344:365-72.

48. Robertson GR, Farrell GC, Liddle C. Sexually dimorphic expression of rat CYP3A9 and CYP3A18 genes is regulated by growth hormone. Biochem Biophys Res Commun. 1998;242:57-60.

49. Elbrecht A, Smith RG. Aromatase enzyme-activity and sex determination in chickens. Science. 1992;255:467-70.

50. Naftolin F, Horvath TL, Jakab RL, Leranth C, Harada N, Balthazart J. Aromatase Immunoreactivity in axon terminals of the vertebrate brain - an immunocytochemical study on quail, rat, monkey and human tissues. Neuroendocrinology. 1996;63:149-55.

51. Peterson RS, Yarram L, Schlinger BA, Saldanha CJ. Aromatase is pre-synaptic and sexually dimorphic in the adult zebra finch brain. Proc R Soc B. 2005; 272:2089-96.

52. Lau ESW, Zhang ZW, Qin MM, Ge W. Knockout of zebrafish ovarian aromatase gene (cyp19a1a) by TALEN and CRISPR/Cas9 leads to all-male offspring due to failed ovarian differentiation. Sci Rep. 2016;6

53. Crews D, Bergeron JM. Role of reductase and aromatase in sex determination in the red-eared slider (Trachemys scripta), a turtle with temperature-dependent sex determination. J Endocrinol. 1994;143:279-89.

54. Ogishima T, Deguchi S, Okuda K. Purification and characterization of cholesterol 7-alpha-hydroxylase from rat-liver microsomes. J Biol Chem. 1987:262:7646-50

55. Jelinek DF, Andersson S, Slaughter CA, Russell DW. Cloning and regulation of cholesterol 7-alpha-hydroxylase, the rate-limiting enzyme in bile-acid biosynthesis. J Biol Chem. 1990;265:8190-7.

\section{Submit your next manuscript to BioMed Central and we will help you at every step:}

- We accept pre-submission inquiries

- Our selector tool helps you to find the most relevant journal

- We provide round the clock customer support

- Convenient online submission

- Thorough peer review

- Inclusion in PubMed and all major indexing services

- Maximum visibility for your research

Submit your manuscript at www.biomedcentral.com/submit
) Biomed Central 